\title{
Micelle-mediated extraction of elderberry blossom by whey protein and naturally derived surfactants
}

\author{
Karolina Śliwa ${ }^{\bowtie}$, Anna Tomaszkiewicz-Potępa, Elżbieta Sikora and Jan Ogonowski \\ Faculty of Chemical Engineering and Technology, Cracow University of Technology, Kraków, Poland
}

\begin{abstract}
Classical methods of the extraction of active ingredients from the plant material are expensive, complicated and often environmentally unfriendly. The micelle-mediated extraction method (MME) seems to be a good alternative. In this work, extractions of elderberry blossoms (Flos Sambuci) were performed using MME methods. Several popular surfactants and whey protein concentrate (WPC) was applied in the process. The obtained results were compared with those obtained in extraction by means of water. Antioxidant properties of the extracts were analyzed by using two different methods: reaction with di(phenyl)-(2,4,6-trinitrophenyl)iminoazanium (DPPH) reagent and Follin's method. Furthermore, the flavonoid content in the extracts was determined. The results confirmed that the MME method with using whey protein might be an alternative method for obtaining, rich in natural antioxidants, plant extracts.
\end{abstract}

Key words: whey protein concentrate, micelle-mediated extraction, elderberry-blossom

Received: 15 October, 2013; revised: 04 December, 2013; accepted: 04 December, 2013; available on-line: 30 December, 2013

\section{INTRODUCTION}

For years, the food, cosmetic and pharmaceutical industries use surface-active compounds for the creation and consolidation various forms of the products, i.e. emulsions, gels, foams. A relatively new application of surfactants is their use for the preparation of intermediates, containing the plant origin active ingredients with a high concentration.

Micelar mediated extraction (MME) is the alternative method to the classic extractions. In this method, instead of an organic solvent, high-performance, but often harmful, an aqueous surfactant solution is used, which in the hydrophobic micelles solubilizes desired ingredient (Paul \& Moulik, 2001). MME is often used for the enrichment of analytes in an environmental studies, for the determination of trace amounts of heavy metals or toxins in biological samples (Madej, 2009; Kiathevest et al., 2009). MME in comparison with the liquid-liquid or solid-liquid extraction methods does not require the use of toxic organic solvents (Szymanowski, 2000). Moreover, MME could be successfully applied to obtain biologically active substances, such as vancomycin, vitamins A, E, $\mathrm{K}, \mathrm{B} 1$, paracetamol, flurbiprofen and salicylic acid, from the plant material (Madej, 2009; Tomaszkiewicz-Potępa et al., 2010).

Quality of this method makes, that the extracted substances can be safely used in foods, pharmaceuticals or cosmetics. Due to the low values of critical micelle con- centration (CMC), the neutral surfactants (nonionic and anionic/cationic systems) are used in very small quantities, which is an additional advantage of this method (Quina \& Hinze, 1999). Nonionic surfactants exhibit the best solubilizing properties. Among factors, which affect the dissolving capacity of the surfactants solution there are the structure and type of surfactant, the presence of electrolytes, presence of other organic materials (polymers and monomers) and the temperature (Quina \& Hinze, 1999)

Milk whey, which is a waste in the dairy industry from years, nowadays more and more often is considered as the valuable raw material for the further processing, for example as a cosmetic raw material. Especially since the high quality of products, requirement for natural beauty treatments, searching for alternative sources of raw materials or new ways of using known ones are main trends observed in the cosmetic industry. Whey is the example of such a raw material, which shows both functional properties and the biological activity. Milk whey is a natural source of valuable cosmetic actives, contains the lactose, proteins, fats, lactic acid, B group vitamins and minerals. Moreover the whey proteins, due to their amphiphilic nature, exhibit surface-active properties (Audic et al., 2005; Wakabayashi et al., 2006; R. Lutz et al., 2009; Sikora et al., 2010; Sikora et al., 2011; G. Herbert, CA 2101622; Patent US 006203805B1).

Elder flower (Sambucus nigra L.) is a wild plant found in various regions of the world. This plant contain diand triterpene glycosides as well as phenolic compounds such as flavonoids, tannins and coumarins. The extracts obtained from the blossoms are rich in rutin and tannins (Stoilova et al., 2007), contain about 1.8\% (rutin, isoquercetin, quercetin glycosides) and phenolic acids. Additionally, it includes the $0.03-0.14 \%$ essential oils, and about $0.85 \%$ triterpene acids (ursolic acid, oleanolic and $20-\beta$ -hydroxy-ursolic acid) (Domokos et al., 2001). The total phenolic content determined by using Folin-Ciocalteu reagent was $194 \mathrm{mg} / \mathrm{g}$ of dry extract per gallic acid (Kim et al., 2003). Analysis of elder flowers revealed the presence of 16 amino acids, of which 9 are most important for our body, including valine, threonine, methionine, isoleucine, leucine, lysine, histidine, phenylalanine. The total amino acid content in the flowers is $8.96 \%$ (Kislichenko \& Vel'ma, 2006). The pharmacological assessment of the diuretic action of Elder flower confirms its traditional application in folk medicine - extracts ob-

e-mail: karola@chemia.pk.edu.pl

* Presented at the 5th Central European Congress of Life Sciences "EUROBIOTECH 2013”, Kraków, Poland.

Abbreviations: DPPH, di(phenyl)-(2,4,6-trinitrophenyl)iminoazanium; MME, micelle-mediated extraction; WPC, whey protein concentrate 
tained from the blossoms increased urine volume and urinary electrolytes' levels in tests with rats (Beaux et al., 1999).

The aim of this work was the study of the possibility of WPC application as an extraction agent in extractions of elderberry blossoms (Flos Sambuci). The micelle-mediated method, using several popular surfactants and WPC, was applied as the extraction method. Antioxidant properties of the extracts were analyzed. The results were compared with those obtained for water extract.

\section{MATERIALS AND METHODS}

Chemicals. Aluminium chloride, sodium hydroxide, sodium nitrite, quercetine were obtained from POCh (Gliwice Poland). The Folin-Ciocalteau's reagent and DPPH were supplied by Sigma Aldrich Sp. z O. o. (Poland). Among the used surfactants there were: Rokanol B2 (Alkoxylated (EO/PO) natural alcohol C16-C18) from PCC Rokita (Poland), Triton X-100 (INCI: Octylphenol Ethoxylate) from DOW Chemicals Co. (DOW Polska Sp. z o.o., Poland), Tego Care CG 90 (INCI: Cetearyl Glucoside) from Evonik Industries (Germany) and Crodesta F160 (INCI: Sucrose Stearate) from Croda Personal Care (Croda Poland Sp. z o.o., Poland). The 80\% WPC was purchased from Bartex Sp. z o.o (Pasłęk, Poland). All the reagents used were of analytical grades.

Extraction procedure. Aqueous extract. Dried elderberry blossoms (3 g) were exhaustively extracted with $200 \mathrm{~cm}^{3}$ of distilled water. The extraction was carried out at room temperature, for $30 \mathrm{~min}$.

Micelle-mediated extraction. Dried elderberry blossoms (3 g) were exhaustively extracted with $200 \mathrm{~cm}^{3}$ of aqueous surfactant solution $(1 \%)$ or solution of WPC $(1 \%, 0.5 \%, 0.25 \%, 0.025 \%, 0.0065 \%)$ CG 90 . Four nonionic surfactants were used: Tego Care CG90 (HLB=11), Sucrose Stearate $(\mathrm{HLB}=16)$, Triton $\mathrm{X}-100(\mathrm{HLB}=13.5)$, Rokanol B2 $(\mathrm{HLB}=6.7)$. Proteins solutions were prepared by WPC dissolving in an appropriate amount of distilled water, next it was mixed by means of magnetic stirrer until completely dissolved and left to proteins swell for $1 \mathrm{~h}$. In all the cases, $0.1 \mathrm{~g}$ of sodium benzoate and $0.5 \mathrm{~g}$ of citric acid were added to the eluent solution. The extraction was carried out in an ultrasonic bath, at room temperature, for $30 \mathrm{~min}$.

In-vitro Antioxidant assay. Flavonoids content were determined using their ability to complex with aluminium chloride according to the method specified by (Hussain et al., 2012). The following procedure was applied: 1 $\mathrm{cm}^{3}$ of the extract was dissolved in $1.1 \mathrm{~cm}^{3}$ of distilled water. Next a $0.3 \mathrm{~cm}^{3}$ of $\mathrm{NaNO}_{2}$ solution (5\%) was added and left for 5 minutes. Then, $0.6 \mathrm{~cm}^{3}$ of $\mathrm{AlCl}_{3}$ solution $(10 \%)$ and after $6 \mathrm{~min}, 2 \mathrm{~cm}^{3}$ of $1 \mathrm{M} \mathrm{NaOH}$ were respectively added. The mixture was diluted with 0.275 $\mathrm{cm}^{3}$ of distilled water and the absorbance of the sample was measured immediately, at $\lambda=510 \mathrm{~nm}$. The spectra was recorded with Macherey Nagel Nanocolor UV/ Vis spectrophotometer. A standard curve was plotted for quercetin and the result were given by quercetin equivalent, ((QE) $\mathrm{g} / \mathrm{dm}^{3}$ ) (Fig. 1). Because of the presence of surfactants, the obtained results were not counted to the dry weight of the extract.

Determination of polyphenols in the extracts was performed with the Folin-Ciocalteau (FC) method described in Grajka's research paper (Grajka, 2000; Cybul and Nowak, 2008). Definite volume $\left(1 \mathrm{~cm}^{3}\right)$ of tested extract was transferred to $10 \mathrm{~cm}^{3}$ volumetric flask. Next, 5 $\mathrm{cm}^{3}$ of the FC reagent was added and held for 4 minutes.

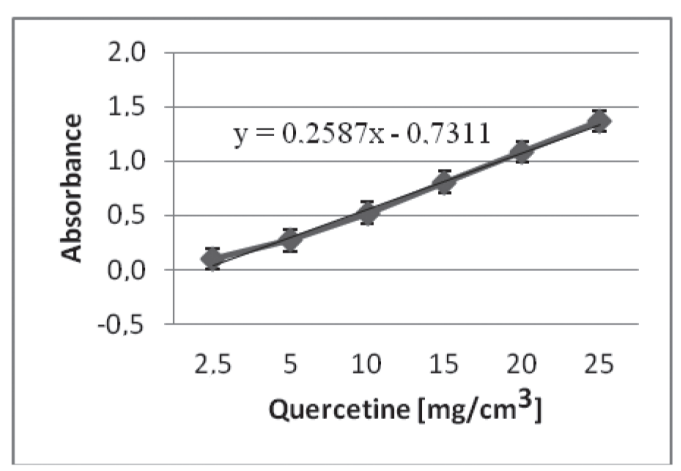

Figure 1. The standard curve for the concentration of quercetine.

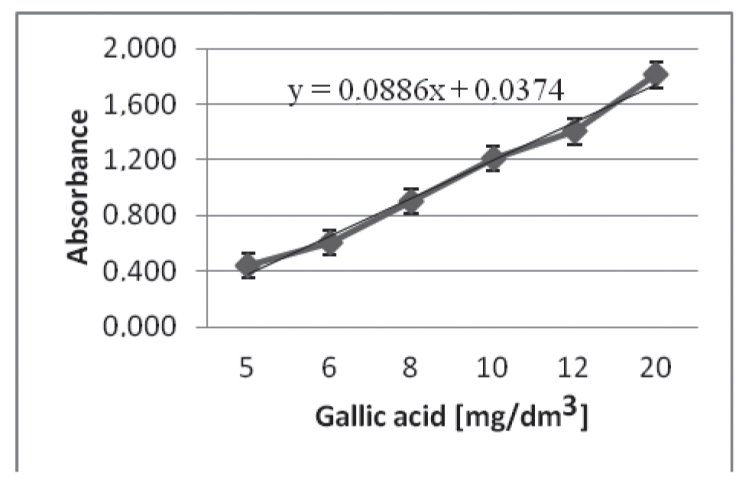

Figure 2. The standard curve for the concentration of gallic acid.

After that, $4 \mathrm{~cm}^{3}$ of $7.5 \%$ sodium carbonate solution was added. The blank sample was also prepared. The test flask were placed in the dark and left for 2 hours. After this time, the absorbance was measured, at a wavelength $\lambda=765 \mathrm{~nm}$. The results were calculated on the content of gallic acid, using the calibration curve (Fig. 2).

The DPPH scavenging potential was estimated as previously described (Shabir et al., 2011) with slight modifications. Definite volume $\left(2 \mathrm{~cm}^{3}\right)$ of DPPH methanol solution $(0.05 \%)$ was added to a $4 \mathrm{~cm}^{3}$ of each extract solution with $4 \mathrm{~cm}^{3}$ of distilled water and left to react at room temperature, in the dark, for $30 \mathrm{~min}$. The absorbance of the obtained mixtures was measured at $\lambda=$ $517 \mathrm{~nm}$.

\section{RESULTS AND DISCUSSION}

Table 1 shows the results of the determination of antioxidant properties of extracts obtained by MME method and for the aqueous extract. All of the results are the average value of three measurements. From the data presented in the table 1 , it could be seen that all applied surfactants have similar, and higher than water, strength of the flavonoid compounds elution (similar $\mathrm{QE}$ value were obtained). It should be underline that the MME extracts contain ten times more flavonoids than the aqueous extract. In case of extracts obtained by whey protein application, as the precursor of micelle, the comparable results were received. Flavonoids content in WPC extracts slightly grows with the increase of its concentration. On the other hand, the type of the surfactant used in MME, has a strong influence on the content of 
Table. 1. Characteristics of the properties of MME extracts.

\begin{tabular}{|c|c|c|c|c|c|}
\hline Surfactant & $\begin{array}{l}\text { Concentration of } \\
\text { surfactant (\%) }\end{array}$ & $\begin{array}{l}\text { Flavonoids content } \\
\text { per quercetine } \\
\left.\text { (QE mg/dm }{ }^{3}\right)\end{array}$ & $\begin{array}{l}\text { Antioxidant activity } \\
(\%)^{* *}\end{array}$ & $\begin{array}{l}\text { Polyphenols con- } \\
\text { tent per gallic acid } \\
\left(\mathrm{mg} / \mathrm{dm}^{3}\right)\end{array}$ & $\begin{array}{l}\text { Not flavonoid-type } \\
\text { polyphenols content } \\
\text { per gallic acid } \\
(\%)^{* * *}\end{array}$ \\
\hline Rokanol B2 & 1 & 32.3 & 33.3 & 119.2 & 73 \\
\hline Triton X-100 & 1 & 32.0 & 36.1 & 101.6 & 69 \\
\hline Tego Care CG 90 & 1 & 30.9 & 4.9 & 70.4 & 56 \\
\hline Sucrose Monostearate & 1 & 32.6 & 5.7 & 127.9 & 75 \\
\hline WPC & 1 & 32.2 & 15.0 & 112.3 & 71 \\
\hline WPC & 0.5 & 31.6 & 43.8 & 55.9 & 43 \\
\hline WPC & 0.25 & 31.3 & 42.9 & 57.6 & 46 \\
\hline WPC & 0.125 & 31.4 & 42.9 & 54.0 & 42 \\
\hline WPC & 0.063 & 31.2 & 39.3 & 51.7 & 40 \\
\hline Demineralized Water* & - & 3.13 & 47.9 & 5.5 & 43 \\
\hline
\end{tabular}

*aqueous extract as a reference sample; **the ability to inhibit the oxidation reaction of DPPH; ***percentage of polyphenols calculated as the ratio of the difference of polyphenols and flavonoids to the total content of polyphenol

polyphenolic compounds in the final extracts. In general, the smallest contents of the polyphenols were obtained using Tego Care CG 90 and less than 1\% WPC solutions. Application of polyethoxylated surfactants, such as Rokanol B2 and Triton X-100 or the derivative of sucrose have resulted in the extraction of a greater amount of polyphenols, mainly non-flavonoid-type.

Concerning the antioxidant properties of the extracts, expressed as the degree of inhibition of DPPH oxidation, the best results were obtained for the samples extracted by whey proteins solutions $(0.125-0.5 \%)$. Contrary, in case of the extract obtained by using 1\% WPC solution, as well as for Tego Care CG 90 and Crodesta F160 extracts, the low value of degree of DPPH oxidation inhibition were observed. However, these samples were characterized by the high concentration of flavonoids and other polyphenols. These findings can be explained by the closing of these antioxidant substances in micelles. A similar effect was observed by Guo (Guo et al., 2007).

Figure 3 shows that the polyphenols content approximately correlate with the flavonoid content. Probably

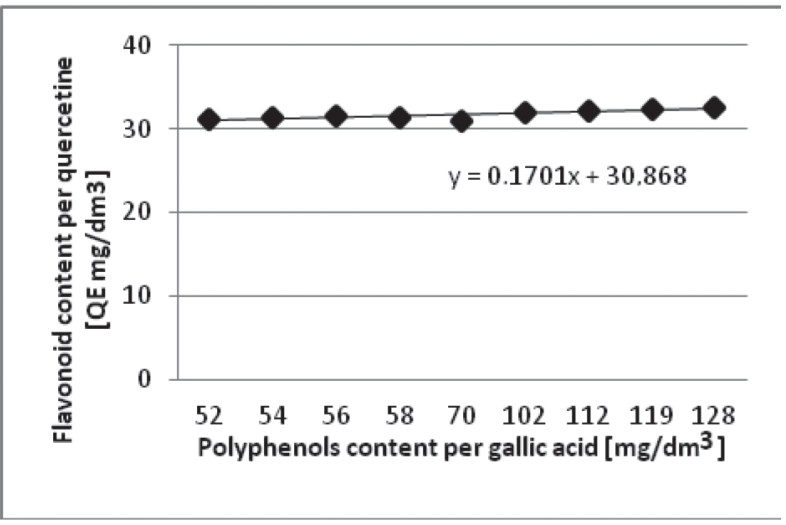

Figure 3. The correlation between the flavonoid and polyphenol contents. depending on the surfactant used, the extracts contain other types of phenolic compounds not only flavonoids. Unfortunately, no straight correlation was found between the composition of extracts and their free radical scavenging activity, determined by DPPH method. It is known (Kaack et al., 2006; Christensen et al., 2008; Kaack et al., 2009), that the elder flowers contain apart from flavonoids and poliphenolic compounds, also unsaturated alcohols, aldehydes, acids, terpenes. These ingredients have influence on antioxidant activity of the extracts. There is a general trend, that the raw materials, which contain monoterpene hydrocarbons, oxygenated monoterpenes and sesquiterpenes show high antioxidant activity. Additionally, the terpenes have a synergistic effect with other antioxidants (Kelen et al., 2008).

\section{CONCLUSION}

The contents of total flavonoids and polyphenols in the MME-extracts were higher than in the case of water extract. The obtained results proved that whey proteins could be the effective agents for MME extraction like a typical surfactants and that the MME method with WPC, as the source of micelles, might be an alternative and a convenient method for the preparation of rich in natural antioxidants plant extracts. Moreover, the obtained extracts do not contain organic solvents and can be directly used in cosmetic compositions, also as a source of whey proteins.

\section{REFERENCE}

Audic JL, Chaufer B, Daufin G (2005) Non-food applications of milk components and dairy co-products: A review. Lait 83: 417-438.

Beaux D, Fleurentin J, Mortier F (1999) Effect of extracts of Orthosiphon stamineus Benth, Hieracium pilosella L., Sambucus nigra L. and Arctostaphylos uva-ursi (L.). Spreng Rats Phytotherapy Res 13: 222-225.

Christensen LP, Kaack K, Frettè CX (2008) Selection of elderberry genotypes best suited for preparation of elderflower extract rich in flavonoids and phenolic acids. Eur Food Res Technol 227: 293-305. 
Collins DF, Mammone T, Marenus KD, Color Access Inc. (2001), Topical compositions containing whey proteins. Patent US: $6203805 B 1$.

Cybul M, Nowak R (2008) Review antioxidant properties analysis methods of plant extracts. Herba Polonica 54: 68-78 (in Polish).

Domokos J, Sipos B, Bela Z, Kiss B (2001) Black stimulus (Sambucus nigra L.) and cosmetics. Kormetika 50: 5-8

Grajka W (2000) Antioxidants in food, pp 219-560, Wyd. Naukow-Techniczne, Warszawa (in Polish).

Guo R, Wei P, Liu W (2007) Combined antioxidant effects of rutin and Vitamin C in Triton X-100 micelles. J Pharm Biomed Anal 43: 1580-1586.

Herbert G (1995) Production process for whey besed detergents, soaps and cosmetics. Canada Patent: CA 2101622.

Hussain M, Fareed S, Ali M, Rahman M (2012) Phytochemical investigation and hyphenated chromatographic analysis of bioactive lupeol and stigmasterol in Sespadula by validated high-performance thin layer chromatography method. I Nat Pharm 3: 46-45.

Kaack K, Christensen LP, Hughes M, Eder R (2006) Relationship between sensory and volatile compounds of elderflower extracts. Eur Food Res Technol 223: 57-70.

Kaack K (2009) Processing of aroma extracts from elder flower. Eur Food Res Technol 227: 375-390.

Kelen M, Tepe B (2008) Chemical composition, antioxidant and antimicrobial properties of the essential oils of three Salvia species from Turkish flora. Bioresource Technol 99: 4096-4104.

Kiathevest K, Goto M, Sasaki M, Pavasant P, Shotipruk A (2009) Extraction and concentration of anthraquinones from roots of Morindacitifolia by non-ionic surfactant solution. Sep Purif Technol 66: 111-117.

Kim D, Jeond S, Lee C (2003) Antioxidant capacity of phenolic phytochemicals from various cultivars of plums. Food Chem 81: 321-326.

Kislichenko VS, Vel'ma VV (2006) Aminoacid composition of flowers, leaves and extract of Sambucus nigra flowers. Chem Nat Compounds 42: 125-126.
Lutz R, Aserin A, Wicker L, Garti N (2009) Double emulsions stabilized by a charged complex of modified pectin and whey protein isolate. Colloid Surfaces 72: 121-127.

Madej K. (2009) Microwave-assisted and cloud-point extraction in determination of drugs and other bioactive compounds. Trends Anal Chem 28: 436-446.

Paul BK, Moulik SP (2001) Uses and applications of microemulsions. Curr Sci India 80: 990-1001.

Shabir G, Anwar F, Sultana B, Khalid ZM, Afzal M, Khan QM, Ashrafuzzaman M (2011) Antioxidant and Antimicrobial Attributes and Phenolics of Different Solvent Extracts from Leaves, Flowers and Bark of Gold Mohar (Delonix regia (Bojer ex Hook.) Raf.). Molecules 16: 7302-7319.

Sikora E, Śliwa K, Ogonowski J, Kalicka D (2011) Study of properties of shampoos containing whey of cow milk. SOFW-Journal 137: $14-20$.

Stoilova I, Wilker M, Stoyanova A, Krastanov A, Stanchev V (2007) Antioxidant activity of extract from elder flower (Sambucus nigra L.). Herba Polonica 53: 45-54.

Szymanowski J (2000) Surfactant enhanced non-classical extraction. J Radioanal Nucl Chem 246: 635-642.

Śliwa K, Sikora E, Ogonowski J (2010) Cosmetic applications of whey. Wiad Chem 64: 507-532.

Tomaszkiewicz-Potępa A, Śliwa K., Śliwa P (2010) Application of surfactants for the extraction of active ingredients from plant material. Czasopismo Techniczne 1-Ch: 343-352 (in Polish).

Quina FH, Hinze WL (1999) Sufractant-mediated cloud point extractions: an environmentally benign alternative separation approach. Ind Eng Chem Res 38: 4150-4168.

Wakabayashi H, Yamauchi K, Takase M (2006) Lactofferin research, technology and applications. Int Dairy J 16: 1241-1251. 